\title{
Inhaltsverzeichnis
}

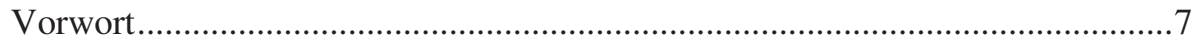

\section{Susanne Kaup}

Bernhard von Waging - sein literarisches Werk als Spiegel

zentraler Themen der benediktinischen Klosterreform

Stephan Haering

Spätmittelalterliche monastische Reforminitiativen in der

benediktinischen Welt. Die Reformen von Santa Giustina in Padua

und von Subiaco sowie das Provinzkapitel zu Petershausen in

kirchenrechtlicher Perspektive

Christine Glaßner

Stift Melk und die Melker Reform im 15. Jahrhundert

Roland Götz

Kloster Tegernsee im 15. Jahrhundert

Ulrike Treusch

Bernhard von Waging. De esu carnium in theologischer

und historischer Perspektive

Victoria Hohenadel

„Sequere me“ - Ein Brief an Bernhard von Waging.

Edition und Untersuchung 


\section{Julia Rinser}

Tegernseer Kosmos: Zwischen Gelehrtengesprächen und

Reformbemühungen. Betrachtungen zum Briefwechsel zwischen

Nikolaus von Kues und den Tegernseer Mönchen Kaspar Ayndorffer und Bernhard von Waging

Philipp Lenz

Die Reformen des Klosters St. Gallen im 15. Jahrhundert

Beda Sonnenberg

Die Entdeckung der Benediktsregel im spätmittelalterlichen

Reformkloster Kastl und in seinem literarischen Umfeld

Victoria Hohenadel

Otium und contemplatio. Reform aus dem Geist der Antike

275

Marc-Aeilko Aris

Lesen und Erneuern - Kulturelle Implikationen

der spätmittelalterlichen Klosterreform

Autorenverzeichnis 303

Personenindex 